\title{
Iontophoretically applied potassium ions as an experimental pain stimulus for investigating pain mechanisms
}

\author{
STEVEN A. HUMPHRIES, NIGEL R. LONG, and MALCOLM H. JOHNSON \\ Massey University, Palmerston North, New Zealand
}

\begin{abstract}
The present study investigated the psychophysical characteristics of potassium iontophoresis and its suitability as an experimental pain stimulus. Experiment 1 investigated the optimal duration of the pain stimulus for reliable reporting across repeated trials and whether the relationship between stimulus and subject response was linear, logarithmic, or a power function. In Experiment 2, the optimal interstimulus interval (ISI) was determined for reliable pain reporting, and stimulus history effects, both in terms of session effects and the effects of immediately preceding stimuli, were evaluated. In Experiment 3, potassium iontophoresis was compared with a sodium iontophoresis control. Linear functions described the stimulus-pain relationship best. No significant differences in the goodness-of-fit coefficients of determination, correlations, or coefficients of variation were found for the stimulus durations of 1,2 , and $4 \mathrm{sec}$. Significant stimulus history effects were found across a session, with adaptation and enhancement of responding for low- and moderate-intensity stimuli, respectively. The effects of the immediately preceding stimuli were suppression or enhancement of pain response, depending on the ISI, the preceding stimulus intensity, and the present stimulus intensity. Potassium iontophoresis was a significantly more effective pain stimulus than was sodium iontophoresis. It was concluded that potassium iontophoresis is a convenient and reliable experimental pain stimulus, which can be presented rapidly and repeatedly with minimal loss in consistency of subject pain report. Potassium iontophoresis provides a tool for investigating the neural modulation of pain in the relative absence of inflammation processes and tissue damage.
\end{abstract}

Pain remains one of our most pervasive and complex health care problems. Nevertheless, major theoretical and practical advances in the understanding of pain have been made through experimental pain research (Zwetnow, 1979).

A number of researchers (e.g., Handwerker \& Kobal, 1993; Lahoda, Stacher, \& Bauer, 1977; Tursky, 1974; Wolff, 1977) have described an ideal pain stimulus as one that (1) can be clearly detected as a pain sensation, (2) can be easily quantified from threshold to tolerance levels, (3) can be presented repeatedly and rapidly with minimal carry-over effects, and (4) is easy to use. It should be safe, and it should not produce any tissue damage but still have demonstrable construct validity with respect to clinical pain.

The experimental pain stimuli most often used are those utilizing thermal, mechanical, electrical, cold pressor, and chemical stimulation. Unfortunately, all of these methods have a number of limitations. For instance, thermal stimulation risks burn injury (Benjamin \& Helvey, 1963 ), and there is a substantial carry-over effect with re-

This research was supported by a New Zealand Vice-Chancellor's Post Graduate Scholarship provided by Massey University to S.A.H. Correspondence should be addressed to S. A. Humphries, Department of Psychology, Massey University, Palmerston North, New Zealand (e-mail: s.a.humphries@massey.ac.nz). peated trials (Hardy, Wolff, \& Goodell, 1967). Painful mechanical stimulation is confounded by pressure sensation (Fiorgione \& Barber, 1971), is often unreliable (Wolff, 1977), and may cause tissue damage.

Electrical stimulation has low ecological validity in that it bears little qualitative relationship with clinical pain. The fact that it excites all nerve fibers, not just those associated with pain stimulation, has lead Geldard (1972) to refer to it as the great "nonadequate" stimulus (p. 324). Most studies use alternating current as the pain stimulus, but there is little consensus over stimulus parameters, making it difficult to compare the results of different studies (Tursky, 1974).

Cold-pressor stimulation allows only a limited number of trials, since a long interstimulus interval (ISI) is typically required for a subject's hand to return to a homeostatic equilibrium before the next trial. In addition, the measure is dependent on blood flow rates, blood pressure, and vasomotor activity (Geldard, 1972; Lahoda et al., 1977). The major disadvantage of ischemic stimulation is the length of time required to complete a single trial, which is often longer than $30 \mathrm{~min}$ (Wolff, 1977). Chemical stimulation risks tissue damage, there is difficulty in precisely quantifying the stimulus (Geldard, 1972; Wolff, 1977), and the long refractory period before a second stimulation is possible limits the number of trials that can be run in a session (Wolff, 1977). 
It is clear from the problems associated with these experimental pain stimuli that none meet all the requirements of an ideal pain stimulus. While it is acknowledged that a great deal of important research has been conducted with these stimuli, the development of more reliable and valid experimental pain stimuli is a priority within the field of experimental pain research.

A seldom-used experimental pain stimulus is the iontophoretic application of potassium ions $\left(\mathrm{K}^{+}\right)$to the skin (Benjamin \& Helvey, 1963). Iontophoresis is the movement of ions under the action of an applied electric current. It provides a noninvasive means of introducing potassium ions through the epidermal barrier.

In numerous clinical studies, the natural pain-producing action of potassium ions has been observed. When intracellular potassium ions are released into the extracellular space, nerve cell membrane potentials are depolarized. Both $\mathrm{C}$ and $\mathrm{A}$-delta pain nerve fibers have been found to be excited by potassium ions (e.g., Kumazawa \& Mizumura, 1977; Uchida \& Murao, 1974), with C fibers being particularly sensitive (Guilbaud, 1988). Examples of pain associated with potassium ion release include tissue rupture during traumatic injury (Benjamin, 1959; Benjamin \& Helvey, 1963), red-blood-cell hemolysis during a cardiac infarction (Keele, 1975; Uchida \& Murao, 1974), and muscle tissue under conditions of muscular activity and anoxia (Uchida \& Murao, 1974).

In an experimental context, the application of potassium chloride solutions to blister bases (Armstrong, Dry, Keele, \& Markham, 1953) and the injection of potassium chloride solutions (Ong, Singer, \& Wallace, 1980) have produced pain reports. The pain associated with potassium ions has been found to be perceptually similar to that produced by acetylcholine, capsaicin, and bradykinin (Ong et al., 1980). Subjective pain reports have ranged from a stinging sensation to an intense burning, depending on the amount of potassium applied. The results of these studies confirm the potential involvement of potassium ions in a pain-processing mechanism.

The few studies that have used potassium iontophoresis to induce pain (e.g., Benjamin \& Helvey, 1963; Coyne \& Peck, 1980; Ong et al., 1980; Voudouris, Peck, \& Coleman, 1985, 1989) have indicated that potassium iontophoresis possesses many of the characteristics required of an experimental pain stimulus. However, the majority of these studies have used the stimulus to investigate pain phemomena, without concentrating on the psychophysics of the stimulus.

Benjamin and Helvey (1963) tested the reliability of potassium iontophoresis by determining pain tolerance levels for subjects for different sessions. The results indicated that although the between-subject variability was large, the within-subject variability was comparatively small. An unpublished pilot study by Voudouris (1981, cited by Voudouris et al., 1985) found that potassium iontophoresis produced no session effects over a 3-day period and that the relationship between stimulus intensity and subject pain report was linear in nature.
The main objectives of the present study were to determine the important operating parameters associated with potassium iontophoresis and the characteristics of subject responding to repeated pain-stimulus trials. In particular, an essential requirement of any experimental pain stimulus is that it produces reliable pain reports in subjects- that is, that subjects can report varying stimulus intensities accurately and consistently over a large number of trials and sessions.

The purpose of Experiment 1 was to determine the psychophysical function that best described the relationship between the iontophoretic pain stimulus and subject pain reports, as well as the optimal duration of the pain stimulus for reliable pain reporting. The purpose of Experiment 2 was to determine the optimal ISI for reliable pain reporting. Stimulus history effects were investigated, in terms of both changes in subject responding across a session and the influence of the immediately preceding stimulus on subject responding to the present stimulus. By running a sodium control group, the purpose of Experiment 3 was to determine the extent to which the perceived pain was a result of the applied potassium ions.

\section{GENERAL METHOD}

\section{Subjects}

A separate group of volunteer students, with ages ranging from 20 to 38 years, was used in each experiment. Prior to participation, all subjects completed a consent form that outlined the general nature of the experiment. The subjects also completed a health checklist to determine if any contraindicating medical conditions were present. They were free to terminate participation at any stage of the study.

\section{Apparatus}

The iontophoretic pain generator consisted of a computercontrolled constant-current power source designed to deliver a selected amount of current, ranging from 0 to $25 \mathrm{~mA}$. The amount of potassium ion delivered is proportional to the applied current. One milliamp-second of current delivers $0.41 \mu \mathrm{g}$ of potassium ions, in accordance with Faraday's law.

The electrodes that were attached to the subject's arm were similar to those described by Benjamin and Helvey (1963) and Voudouris et al. (1985). The cathode consisted of a silver plate $(4 \times 13 \mathrm{~cm})$ covered with several layers of saline-saturated medical gauze $(4 \% \mathrm{w} / \mathrm{v}$ sodium chloride) placed against the palmar surface of the subject's arm. The anode consisted of a silver plate suspended in a plastic bowl with no base. This bowl was placed against the volar surface of the subject's arm. The subject's skin acted as the base for the bowl. This arrangement allowed a potassium chloride gel $(3 \% \mathrm{w} / \mathrm{v}$ potassium chloride, $1.0 \% \mathrm{w} / \mathrm{v}$ biological grade agar) in the bowl to be in direct contact with the subject's skin. The contact surface area of the gel was $12.5 \mathrm{~cm}^{2}$. The use of the potassium chloride solution in gel form prevented the solution from leaking out of the electrode bowl, permitting the electrodes to be attached to the subject's arm without the need for excessive pressure.

\section{Dependent Variable Measures}

All pain reports were recorded using a $15-\mathrm{cm}$ visual analogue scale (VAS) on a computer screen. A VAS was selected because it is easy to use, has high face validity, and has consistently been shown to be reliable and precise (McCormack, Horne, \& Sheather, 
1988). The sensory scale anchors were no pain sensation at all and very strong sensation of pain. No intervals were marked on the scale between the anchors.

The advantage of this magnitude estimation procedure is that, in contrast to threshold or tolerance measures, it provides stimulus response information over a range of stimulus levels, and the pain levels are ecologically valid with respect to most clinical pain.

\section{Procedure}

A standard protocol was adhered to on all sessions. Because pain responding has been shown to vary as a function of the time of day, the subjects were tested at the same time each day in order to avoid any possible diurnal confounds (Procacci \& Maresca, 1984). Prior to the application of the electrodes, the palmar and volar surfaces of the subject's arm were prepared by light scrubbing with warm soapy water followed by an acetone $/ 90 \%$ alcohol solution. This procedure lowered and stabilized the resistance of the skin so that the required amperages could be obtained from the constant-current generator without excessively high or variable voltages.

The subjects were seated at a table with the electrodes attached to the dominant arm. This arm rested on the table throughout the experiment. Positioned by the free arm of the subject was a cutoff switch, which could be used to terminate any of the stimulus administrations immediately. The cutoff switch was not used during any of the experiments.

A familiarization session the day before the first experimental session was provided in order to give the subjects an opportunity to learn the nature of the tasks, to become familiar with using the VAS, and to reduce possible high levels of anxiety associated with an unknown pain stimulus. In an absolute magnitude estimation procedure, the subjects were asked to rate on the VAS how painful each stimulus was. They were informed that the stimuli intensities would randomly vary and that it would not be possible to predict any pattern.

In Experiments 1 and 2, only four stimulus intensities were used for each subject, and these were presented in a random order. M. Teghtsoonian and R. Teghtsoonian (1983) have cautioned that successive judgments of the same stimulus may not be independent because of familiarization with the stimulus set. Consequently, the steps between stimuli of adjacent intensity were kept small enough to reduce the categorization of stimuli and responses on the basis of remembered responses. That is, there was always some response overlap between adjacent intensity stimuli. The same sequence of trials was used in all experimental sessions, and the second half of a session repeated the sequence of trials in the first half.

A subject's responses during the familiarization session were used to determine the range of stimulus levels that the subject would be exposed to over the following experimental sessions. Stimulus ranges were individually selected for each subject so that responding was mostly away from the ends of the scale, thereby reducing anchor effects.

Immediately prior to each experimental session, the subjects were administered the range of stimuli that would be delivered during the experiment. Along with the preparatory cleaning of the subject's arm, this helped to lower and stabilize electrode resistance (Tursky, 1974). For most subjects, resistance was $5 \mathrm{k} \Omega$ or less prior to the start of each session.

All pain stimuli were preceded by a warning beep on the computer $1 \mathrm{sec}$ prior to the start of the pain stimulus. For Experiment 1 , the duration of the stimulus varied from 1 to $4 \mathrm{sec}$. For Experiments 2 and 3, the duration of the stimulus was set at $1 \mathrm{sec}$. For all stimulus intensities, the current was ramped up and down over a $500-\mathrm{msec}$ period. The subjects responded to indicate the intensity of perceived pain immediately after the end of the stimulus presentation by moving a cursor on the computer-presented VAS. All responses were automatically recorded by computer.

\section{EXPERIMENT 1}

To avoid excessive pain for subjects and to minimize possible carry-over effects, a short-duration pain stimulus is desirable. However, there is also the possibility that short-duration stimuli do not give subjects sufficient time to make a reliable judgment. In an earlier study (Humphries \& Johnson, 1990), some subjects reported that if the 1-sec stimulus duration had been longer, they might have been able to judge the pain sensation more consistently. However, Price and Tursky (1975) reported that for electric shock the correlation between pain reports for stimulations of 1 and $2.5 \mathrm{sec}$ was 0.98 . This indicates that the subjects could judge the short-duration stimuli as consistently as the longer duration.

Psychophysical pain studies most frequently report power functions to describe the relationship between pain-stimulus levels and subject report (e.g., Cross, Tursky, \& Lodge, 1975; Rollman \& Harris, 1987), although the extent to which this simply reflects the ability of a power function to fit nearly any monotonically increasing trend remains contested (Jones, 1980; Poulton, 1968). If goodness of fit is the criterion for implying that a function reflects some underlying psychophysical relationship, then the onus is to demonstrate that no alternative functions with the same number of constants can provide a similar goodness of fit (McCallum \& Goldberg, 1975; Poulton, 1968). Voudouris et al. (1985) reported a linear relationship for iontophoretic pain. However, the extent to which the relationship could have been described by a logarithmic or power function was not provided.

A goal of Experiment 1 was to determine the stimulus duration that provided the most consistent subject responding over repeated trials for pain induced by potassium iontophoresis. Linear, logarithmic, and power functions were also calculated, since all three functions have been reported for pain perception (e.g., Kenshalo, Anton, \& Dubner, 1989; Price \& Tursky, 1975; Rollman \& Harris, 1987; Stam, Petrusic, \& Spanos, 1981).

\section{Method}

In each of three daily sessions, the subjects were exposed to three blocks of 20 random-intensity stimuli. For each subject, only four intensity levels were used. Because of individual variation in pain responsivity, the stimulus intensity levels were not the same for all subjects. Stimulus intensities ranged from 4 to $22 \mathrm{~mA}$ $\left(1.64-9.02 \mu \mathrm{gK}^{+} / \mathrm{sec}\right)$. Within each block, all stimuli were 1,2 , or $4 \mathrm{sec}$ in duration. The blocks were presented in counterbalanced order across daily sessions for the group of subjects. Relatively long ISIs of $40 \mathrm{sec}$, and 4-min rest periods between trial blocks, were intended to minimize any potential carry-over effects between trials.

\section{Results and Discussion}

At the conclusion of the experiment, all subjects reported that they were unable to detect any stimulus categories, and that they could perceive no pattern to the stimulus presentations. For most subjects, the pain reports to the higher level stimuli were somewhat lower 
than those during the familiarization session when the stimulus levels were set for each subject.

Linear, logarithmic, and power functions were calculated by averaging subject results over all sessions and all stimulus durations. Semi-log and double-log coordinates were used to determine the linearity of the logarithmic and power functions, respectively. The coefficient of determination $\left(r^{2}\right)$ was used as a measure of goodness of fit for all three functions.

Table 1 shows the goodness of fit for the linear, logarithmic, and power functions, with the exponent for the power function. Individual, as well as group, results are reported because group data are often not representative of individual behavior (Algom, Raphaeli, \& Cohen-Raz, 1986; McCallum \& Goldberg, 1975). This is especially true in pain research, where vast individual differences are often found (e.g., Rollman \& Harris, 1987).

Overall the linear function provided the best description of the stimulus-response relationship, with the difference between the linear and power function approaching significance $[t(5)=2.54, p<.06]$. (These same trends were found in Experiments 2 and 3, where there were significant differences between the linear and power function coefficients of determination.) Though there can be large individual differences with pain perception, the individual results were generally consistent with the group data.

On the basis of the coefficients of determination in Table 1, all three functions tested could be considered to provide an adequate description of the stimulus-response relationship. This illustrates the danger of presenting a single function in support of a particular perceptual model (Jones, 1980). The relationship between pain stimuli and pain report would be expected to be monotonic, and this monotonicity alone is enough to produce high goodness-of-fit correlation values (Parker, Casey, Ziriax, \& Silberberg, 1988). At the very least, it is necessary to demonstrate that a particular function provides a better description of the data than do alternative functions.

The limited stimulus and response range used in the present study restricts the ability to differentiate the goodness of fit of alternative functions (R. Teghtsoon-

Table 1

Coefficients of Determination ( $\left.\boldsymbol{r}^{2}\right)$ for Linear, Logarithmic, and Power Functions for the Relationship Between Iontophoretic Potassium Stimulus and Pain Report on the Pain-Intensity VAS in Experiment 1

\begin{tabular}{cccc} 
& \multicolumn{3}{c}{ Function } \\
\cline { 2 - 3 } Subject & Linear & Logarithmic & Power \\
\hline 1 & .74 & .74 & $.61(2.98)$ \\
2 & .90 & .90 & $.71(3.26)$ \\
3 & .88 & .85 & $.85(3.46)$ \\
4 & .85 & .83 & $.83(2.76)$ \\
5 & .77 & .79 & $.72(4.69)$ \\
6 & .92 & .81 & $.90(2.67)$ \\
Average & .84 & .82 & $.77(3.30)$ \\
\hline
\end{tabular}

Note-Exponents for power functions given in parentheses ian \& M. Teghtsoonian, 1986). Nevertheless, responses for most subjects covered most of the VAS, with an average response range of $122 \mathrm{~mm}$ on the $150-\mathrm{mm}$ VAS, a mean response (averaged over all subjects) of $56 \mathrm{~mm}$, and a standard deviation of $37 \mathrm{~mm}$. Thus, even with this relatively large range in reported pain-a range with clinical validity as people suffering from pain frequently experience pain within this region-all three functions were capable of providing a good description of the stimulus-pain relationship.

It is possible that the more frequently reported power function for pain perception (e.g., Rollman \& Harris, 1987; Stevens, Carton, \& Shickman, 1958) could have provided the more accurate description of the stimuluspain relationship if a larger stimulus range had been used. In addition, the subjects in the present experiments were not verbally prompted in any way to make ratio judgments on the VAS, so the methodology did not encourage the resultant subject data to fit a power function (Laming, 1989; Poulton, 1979, 1984).

The exponent values for the power functions ranged from 2.67 to 4.69 , with a mean of 3.30 (Table 1). This matches the variability found by Rollman and Harris (1987), who reported individual power exponents for electric shock pain from 0.29 to 9.93 for a group of 40 subjects.

Power exponents based on group data have ranged from a low of 0.7 (Beck \& Rosner, 1968) to a high of 4.5 (Stevens, 1965), though the majority of pain studies normally report values below 3.0 (e.g., Algom et al., 1986; Jones \& Gwynn, 1984). Our relatively high mean value of 3.30 may be a characteristic of potassium iontophoresis, or it may be partly attributable to the small range of stimulus intensities used. A narrow stimulus range within a session has been found to produce somewhat higher power exponents (Poulton, 1968, 1975; R. Teghtsoonian, 1973). In addition, the present study did not use a threshold correction factor for the power function. Threshold correction factors can lower the exponent value (Beck \& Rosner, 1968).

Nevertheless, our results do support the description by Voudouris et al. (1985) that the relationship between potassium iontophoretic stimulation and pain report is linear. Figure 1 shows the linear regression line of best fit for all 6 subjects in Experiment 1. In terms of the regression equation parameters, there is a great deal of individual variability, consistent with previous pain studies (e.g., Rollman \& Harris, 1987). For instance, at $10 \mathrm{~mA}\left(4.1 \mu \mathrm{gK}^{+} / \mathrm{sec}\right)$, Subject 2 reported $122 \mathrm{~mm}$ on the VAS, whereas, at the higher stimulus level of $16 \mathrm{~mA}$ $\left(6.6 \mu \mathrm{gK}^{+} / \mathrm{sec}\right)$, Subject 6 rated this only at $20 \mathrm{~mm}$. For all subjects, the linear regression function was an accurate description of the stimulus-response relationship. The correlations in Figure 1 are based on the mean responses for each of the four stimulus levels that each subject received.

Because the linear function provided the best fit (Table 1), the linear function correlations were used as a measure of subject reliability in responding across the 

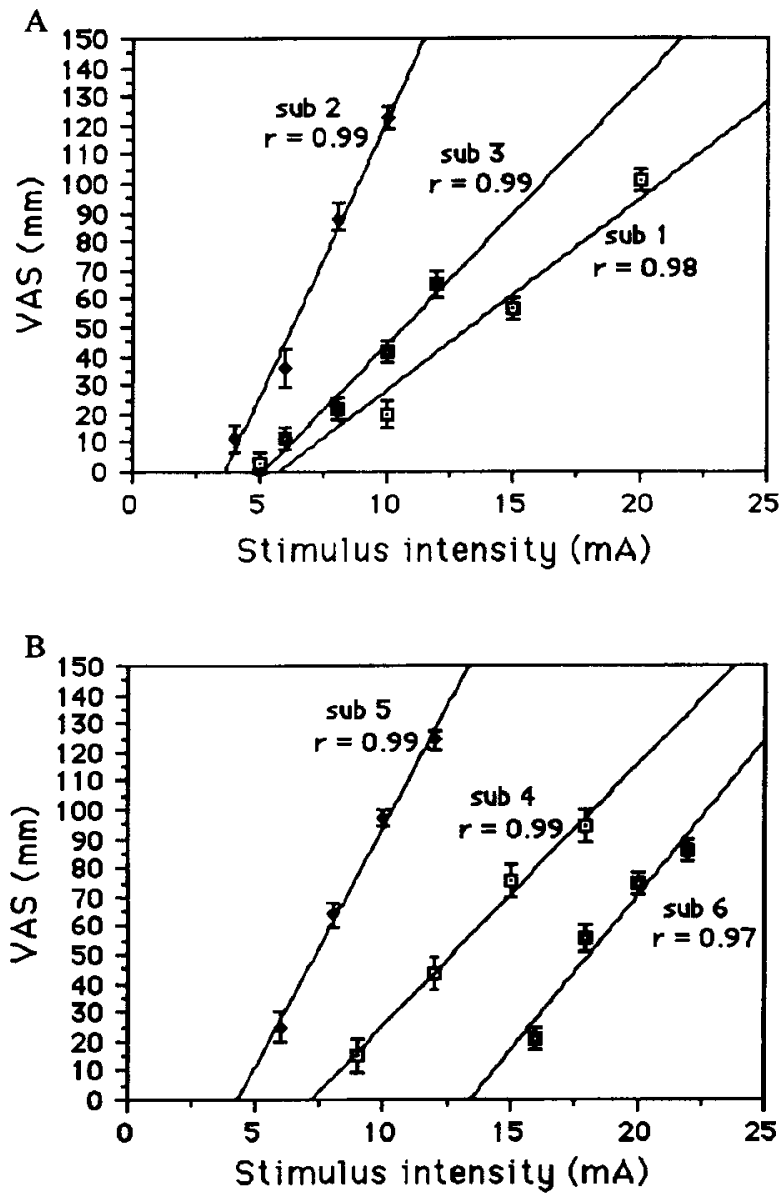

Figure 1. VAS pain responses as a function of stimulus intensity for Experiment 1. Each data point is the arithmetic mean of 15 responses. For all subjects, the linear regression equation is an accurate representation of the stimulus-response relationship, with correlations ranging from .97 to .99 . The error bars are the standard error of the mean. The figure is divided into Parts $A$ and $B$ for clarity of presentation.

stimulus durations of 1,2 , and 4 sec. Averaging the results for all subjects over each session, the correlation coefficients were not statistically different $(p=.69)$ and were consistently high for all stimulus durations $(r s=$ $.91, .92$, and .91 , for the $1-, 2-$, and 4-sec stimulus durations, respectively).

However, these correlations provide a measure of fit to the regression line, not the individual stimulus levels, even with high correlations in the .90 s. In order to overcome this limitation, coefficients of variation (CVs) were calculated to provide a direct measure of response variability for each stimulus intensity. Initially, all responses were converted to a ratio score by dividing response by stimulus so that the standardized subject data could be combined. A CV was then calculated for each subject for each stimulus level for each session. An overall $\mathrm{CV}$ for each condition was calculated by averaging all subject $\mathrm{CVs}$.

The CV is known to be inversely proportional to stimulus intensity (Gescheider, 1988). This inverse relation- ship was found in Experiment 1, with the coefficient of variation decreasing from $78 \%$ for the lowest stimulus intensity to $13 \%$ for the highest stimulus intensity; this was a significant change in the coefficient of variation $[F(3,15)=22.17, p<.01]$, with a significant linear trend $[t=5.38, p<.01]$. Although the CV changed significantly as a function of stimulus intensity, the duration of the stimulus had no significant effect. The CVs for the $1-, 2-$, and $4-\sec$ stimulus durations were $30.9 \%, 26.7 \%$, and $33.3 \%$, respectively. There was no significant interaction between stimulus intensity and stimulus duration. On the basis of the linear correlation coefficients and the CVs, it would appear that increasing stimulus duration from 1 to $4 \mathrm{sec}$ produces no systematic increase in consistency of subject responding to repeated trials of the pain stimuli.

Therefore, despite the self-reports by earlier subjects that a longer duration stimulus may assist in producing more consistent pain reports, there is no evidence that increasing stimulus duration improves the reliability of subject reports over repeated trials. This is consistent with the results obtained by Price and Tursky (1975), who found a constant high reliability in responding despite manipulations of stimulus duration from 1 to $2.5 \mathrm{sec}$.

Given the desirability of short-duration stimuli (i.e., $1 \mathrm{sec}$ ), and the fact that there is no advantage in longer duration stimuli, 1-sec duration stimuli were used in Experiments 2 and 3 .

\section{EXPERIMENT 2}

The ability to present the pain stimulus repeatedly and over a short period of time is important in terms of both convenience and the statistical power gained from repeated trials. For example, the ability to rapidly repeat trials becomes particularly critical in signal detection studies, where large numbers of trials are an essential requirement for an adequate analysis (e.g., Clark \& Goodman, 1974; Lloyd \& Appel, 1976) or where time is critical, such as monitoring the ongoing effects of an analgesic. While it is desirable that ISIs be as short as possible, the confounding influence of carry-over effects, which may increase with shorter ISIs, also needs to be considered.

Pain responsivity is influenced by stimulus history in a complex manner that involves both peripheral and central processes (Price, 1988; Wall, 1988). Depending on the type of stimulus, stimulus intensity, duration, rate of delivery, and the site of stimulation, the results can be either hyperalgesia or hypoalgesia (e.g., LaMotte, Thalhammer, \& Robinson, 1983; Torebjörk, LaMotte, \& Robinson, 1984). For example, with thermal stimulation, a lowering of perceived stimulus intensity has been found for shorter ISIs (Chudler, Anton, Dubner, \& Kenshalo, 1990; LaMotte \& Campbell, 1978).

Repeated pain trials can produce long-lasting session changes in responding to painful stimuli. Lahoda et al. (1977) found habituation, with higher pain thresholds and tolerances for electric shock during the second 
block of an experimental session. Higashiyama and Tashiro $(1987,1989)$ not only found a session effect for electric shock, they also reported a stimulus intensity interaction. For low-intensity pain stimuli, the subject magnitude estimates remained constant, independent of session block. For below-pain-threshold stimuli, the subject magnitude estimates decreased across the session.

In addition to effects that occur across a session, studies have also shown that neural activity and pain reports may be influenced by the intensity of the immediately preceding stimulus. LaMotte and Campbell (1978) reported that, for thermal stimuli, pain ratings were greater when the preceding stimulus was low, relative to when it was high.

Experiment 2 investigated both enduring session effects and the effects of immediately preceding pain stimuli on pain perception as a function of ISI.

\section{Method}

In each of three daily sessions, 6 subjects were exposed to 60 1 -sec stimuli. As in Experiment 1, for each subject, only four stimulus intensity levels were used. Stimulus intensities ranged from 7 to $16 \mathrm{~mA}\left(2.87-6.56 \mu \mathrm{gK}^{+} / \mathrm{sec}\right)$ for 5 of the subjects and 16-22 $\mathrm{mA}\left(6.56-9.02 \mu \mathrm{gK}^{+} / \mathrm{sec}\right)$ for Subject 6 . Within a session, all ISIs were 10,20 , or $40 \mathrm{sec}$. The order of the ISI sessions was counterbalanced across the subject group, with each subject receiving each of the ISI sessions once.

\section{Results and Discussion}

All subjects reported that they were unable to detect any stimulus categories and that they could perceive no pattern to the stimulus presentations. Coefficients of determination for the linear, logarithmic, and power functions for individuals were consistent with the overall group results (Table 2). The linear function provided a significantly better description of the stimulus-response relationship than did the power function $[t(5)=2.72$, $p<.05]$, and the power function exponent was again somewhat higher than that reported in most other studies. These results replicated, with 6 previously untested subjects, the findings of Experiment 1.

Linear function goodness-of-fit coefficients of determination were obtained across the three treatment conditions, as in Experiment 1. For the ISIs of 10, 20, and $40 \mathrm{sec}$, there were no significant differences in the co-

Table 2

Coefficients of Determination $\left(r^{2}\right)$ for Linear, Logarithmic, and Power Functions for the Relationship Between Iontophoretic Potassium Stimulus and Pain Report on the Pain-Intensity VAS in Experiment 2

\begin{tabular}{cccc}
\hline & \multicolumn{3}{c}{ Function } \\
\cline { 2 - 4 } Subject & Linear & Logarithmic & Power \\
\hline 1 & .90 & .90 & $.85(2.46)$ \\
2 & .85 & .85 & $.72(2.68)$ \\
3 & .86 & .83 & $.77(3.07)$ \\
4 & .92 & .90 & $.85(2.20)$ \\
5 & .77 & .76 & $.71(2.27)$ \\
6 & .74 & .71 & $.77(5.71)$ \\
Average & .84 & .83 & $.79(3.06)$ \\
\hline
\end{tabular}

Note--Exponents for power functions given in parentheses.
Table 3

Ratio and VAS Scores as a Function of ISI, Session Block, and Stimulus Level in Experiment 2

\begin{tabular}{|c|c|c|c|c|c|c|}
\hline \multirow[b]{3}{*}{ Stimulus Level } & \multicolumn{6}{|c|}{ ISI } \\
\hline & \multicolumn{2}{|c|}{$10 \mathrm{sec}$} & \multicolumn{2}{|c|}{$20 \mathrm{sec}$} & \multicolumn{2}{|c|}{$40 \mathrm{sec}$} \\
\hline & Ratio & VAS & Ratio & VAS & Ratio & VAS \\
\hline \multicolumn{7}{|c|}{ First-Half Session Block } \\
\hline Low & 3.4 & 32 & 4.0 & 36 & 3.7 & 34 \\
\hline Moderate & 7.0 & 104 & 6.8 & 100 & 6.7 & 100 \\
\hline \multicolumn{7}{|c|}{ Second-Half Session Block } \\
\hline Low & 3.5 & 32 & 3.9 & 35 & 2.9 & 27 \\
\hline Moderate & 7.4 & 110 & 6.8 & 101 & 7.0 & 104 \\
\hline
\end{tabular}

efficients of determination $(p=.20)$. The correlations for the three conditions were $.92, .92$ and .93 , respectively. The CVs were $35.8 \%, 30.9 \%$, and $31.1 \%$ for the $10-, 20$-, and 40-sec ISIs, respectively; none were significantly different $[F(2,4)=1, p=.60]$.

In order to investigate pain response changes over a session, all responses were converted to ratio scores by dividing response by stimulus level. Sessions were dichotomized into first-half and second-half session blocks, each block consisting of 30 trials. The applied pain stimuli were dichotomized as being of either low or moderate intensity. The low-intensity stimulus consisted of the two lower stimulus levels that were presented to each subject, and the moderate-intensity stimulus consisted of the two higher stimulus levels that were presented to each subject. The stimulus levels were dichotomized in order to increase the sample size of the group means. The ratio scores and VAS scores obtained are presented in Table 3.

A three-way $(2 \times 2 \times 3)$ repeated measures analysis of variance (ANOVA) determined the effects of stimulus level, session block, and ISI. The only significant main effect was for stimulus level, in which the moderate-intensity stimuli had a higher response ratio (7.0) than did the low-intensity stimuli $(3.6)[F(1,5)=94.37$, $p<.01]$; however, this was not of direct interest. The lack of a main or interaction effects for ISI contrasts with the results of LaMotte and Campbell (1978) and Chudler et al. (1990), though they had used a different and greater ISI range (25-225 sec and 30-180 sec, respectively). However, our failure to find a significant interaction effect may be due to the lack of experimental power with only 6 subjects. For instance, the drop in ratio score for the low-intensity stimulus condition for our sample occurred almost entirely under the 40-sec ISI condition. These potential interactions need to be investigated further with larger subject numbers.

There was a significant interaction between session block and stimulus level $[F(1,5)=8.92, p<.05]$. In terms of the ratio scores, for the low-intensity stimuli, there was an $8.2 \%$ decrease in responding to the pain stimulus from the first-half to the second-half session block (ratio scores dropped from 3.7 to 3.4 ); for the moderateintensity stimuli, there was a $3.2 \%$ increase (ratio scores increased from 6.8 to 7.1 ). While significant, these changes 
Table 4

Ratio and VAS Scores as a Function of the Present and Immediately Preceding Stimulus Pain Levels in Experiment 2

\begin{tabular}{|c|c|c|c|c|c|c|}
\hline \multirow{3}{*}{$\begin{array}{c}\text { Preceding } \\
\text { Stimulus Level }\end{array}$} & \multicolumn{6}{|c|}{ ISI } \\
\hline & \multicolumn{2}{|c|}{$10 \mathrm{sec}$} & \multicolumn{2}{|c|}{$20 \mathrm{sec}$} & \multicolumn{2}{|c|}{$40 \mathrm{sec}$} \\
\hline & Ratio & VAS & Ratio & VAS & Ratio & VAS \\
\hline \multicolumn{7}{|c|}{ Low Stimulus Level } \\
\hline Low & 2.6 & 22 & 3.6 & 29 & 2.9 & 25 \\
\hline Moderate & 4.0 & 39 & 4.2 & 39 & 3.5 & 34 \\
\hline \multicolumn{7}{|c|}{ Moderate Stimulus Level } \\
\hline Low & 7.2 & 108 & 7.0 & 104 & 7.1 & 106 \\
\hline Moderate & 7.2 & 108 & 6.5 & 97 & 6.5 & 97 \\
\hline
\end{tabular}

were small in terms of changes in VAS responding: there was a decrease from an average of 34 to $31 \mathrm{~mm}$ for the low-intensity stimuli, and an increase from 101 to $105 \mathrm{~mm}$ for the moderate-intensity stimuli.

These results are similar to the findings of Higashiyama and Tashiro $(1987,1989)$ in that differential session effects have been found for different stimulus intensities. However, their studies found a decrease in magnitude estimates across sessions for low-intensity (prepain) stimuli whereas magnitude estimates remained constant for higher intensity (painful) stimuli (their higher intensity stimuli being 2.8 to 3.8 times the pain threshold current). In contrast, in the present experiment, all stimuli were perceived as painful - that is, all stimulus intensity levels were rated higher than zero on the VAS scale. Our results show that it is possible to adapt to a low level of a pain stimulus while, at the same time, showing an enhanced response to a higher level of the same pain stimulus.

Ratio scores were also used to evaluate the influence of the immediately preceding stimulus on responding to the present stimulus. Immediately preceding stimuli and present stimuli were both dichotomized as being of either low or moderate pain intensity. The ratio scores and VAS scores obtained are presented in Table 4.

A three-way $(2 \times 2 \times 3)$ repeated measures ANOVA of the ratio scores determined the effects of precedingstimulus intensity, present-stimulus intensity, and ISI on responding. There were significant interactions between the preceding and present stimuli $[F(1,5)=29.11, p<$ $.01]$ and between the ISI and preceding stimuli $[F(2,10)=$ $7.55, p<.01]$. There was a significantly higher pain response to a low-intensity stimulus when it was preceded by a moderate-intensity stimulus, relative to when it was preceded by a low-intensity stimulus. This effect was significant for all ISIs [10-sec ISI, $t(5)=3.62, p<.05$; 20 -sec ISI, $t(5)=3.30, p<.05 ; 40$-sec ISI, $t(5)=3.13$, $p<.05$ ], and it was greatest for the $10-\mathrm{sec}$ interval. Figure 2 shows the change in ratio scores.

Responses to moderate-intensity stimuli changed significantly only for the 40 -sec ISI $[t(5)=3.40, p<.05]$, with a lower pain response following a moderateintensity stimulus, relative to following a low-intensity stimulus. This ISI $\times$ preceding-stimulus interaction contrasts with the study of LaMotte and Campbell (1978), who found that pain ratings always varied inversely with the intensity of the preceding stimulus.

The effect of immediately preceding stimuli can account for a large proportion of the variance in subject responding. For example, with a 10-sec ISI for low-intensity stimuli preceded by low-intensity stimuli, the standard deviation of the ratio scores was 1.58 , whereas the systematic change in ratio score due to the change in intensity of the preceding stimulus from the low to the moderate condition was 1.35 (Figure 2).

The relatively large change in ratio score for low-intensity present stimuli with a 10-sec ISI (Figure 2) is consistent with our largest CV of $35.8 \%$ for this ISI. In designing a study, a balance needs to be made between short ISIs allowing greater trial numbers and the possibility of increased "unexplained" response variability due to carry-over effects at these shorter time intervals. Consideration also needs to be given to response changes across a session (Table 3). On the basis of our results, one possible strategy with potassium iontophoresis would be to use low ISIs $(10-20 \mathrm{sec}$ ), with only stimuli in the moderate-intensity range, thus avoiding the relatively larger carry-over effects and session effects found for low-intensity stimuli. Of course, other factors need to be considered in addition to these psychophysical requirements. Nevertheless, such a strategy could be particularly advantageous when attempting to track changes in pain, as in following the time course of an analgesic, where a large number of unbiased responses are required repeatedly within short "time windows."

The pooling of potassium ions at the site of neural excitation from the preceding stimulus does not explain the observed carry-over effects for two reasons. First, when the pain stimulus is ramped off, the pain perception dies away immediately, regardless of stimulus intensity. This indicates that the small amount of potassium applied (typically, $3 \mu \mathrm{g}$ ) is cleared rapidly from the site of neural

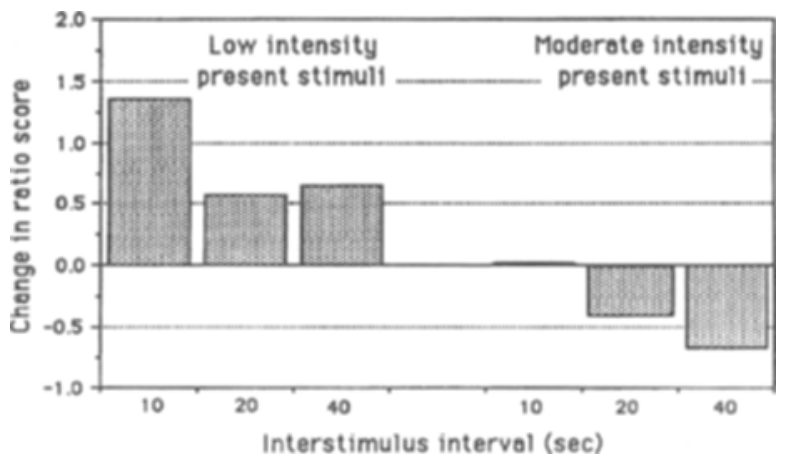

Figure 2. The change in ratio scores as a function of ISI, intensity level of the present stimulus, and intensity level of the immediately preceding stimulus in Experiment 2. Change in ratio score $=$ ratio scores of (present stimuli preceded by moderate-intensity stimuli) (present stimuli preceded by low-intensity stimuli). Positive scores indicate that responding to the present stimulus is higher if the previous stimulus was of a moderate rather than low intensity. 
activation. Given this apparent rapid clearance, it is unlikely that residual amounts of potassium 10,20, or $40 \mathrm{sec}$ later could have much influence.

Second, a pooling of potassium would be expected to increase pain reports when moderate-intensity stimuli are preceded by moderate-intensity stimuli, relative to when they are preceded by low-intensity stimuli. In fact, there is no significant difference at the 10 - and 20 -sec intervals. At the $40-\mathrm{sec}$ interval, there is even a significant decrease in responding. The lack of increase in pain reports for the moderate-intensity stimuli could not be attributed to a ceiling effect, because most of the VAS ratings for these stimuli were some distance from the upper scale anchor.

The changes induced by the preceding stimuli were able to be detected with ISIs as short as $10 \mathrm{sec}$. This indicates that the onset and offset of the influence of the preceding stimuli were relatively rapid. These "micro changes" need to be distinguished from the longer lasting session effects. For instance, the reported time course for most hyperanalgesic and hypoanalgesic states is normally in the order of minutes and even hours (Hardy, Wolff, \& Goodell, 1950; LaMotte, Shain, Simone, \& Tsai, 1991). An area of investigation would be to determine whether the changes detected in the present experiment represent relatively transient nociceptive neural changes of sensitization and adaptation occurring at the peripheral level or whether they are more central in nature.

Alternative explanations, independent of pain-processing mechanisms, also need to be considered for these effects. There are a number of general response biases that could have influenced responding on the magnitude estimation task. Previous pain research indicates that these effects can be complex. For example, time-order errors (TOEs) in pain perception are a function of both stimulus duration and ISI. Geertsma (1958) reported a positive TOE for 2.5-sec ISIs and negative TOEs for 14.5sec ISIs for electric shock pain. Jones, Planas, and Anuza (1982), also using electric shock pain, found a positive TOE for prepain stimuli, zero for faintly painful stimuli, and a negative TOE for moderately painful stimuli.

In the present experiment, the results in Figure 2 for the low-intensity stimuli are consistent with a centering bias, with responses biased in the direction of the immediately preceding stimulus. However, the moderateintensity stimuli results are not consistent with such an interpretation. In addition, the relatively large effects obtained in the present experiment (up to $50 \%$ changes in the ratio score for the $10-\mathrm{sec}$ low-intensity stimuli) make it unlikely that these changes could be explained purely in terms of some general response bias. For instance, Geertsma's (1958) study reported only a $1 \%-3 \%$ change in reported pain due to TOEs.

\section{EXPERIMENT 3}

It is important to determine how much of the pain produced by potassium iontophoresis is directly attributable to the potassium ions, since direct current itself can be a pain stimulus. Vierck, Cooper, Franzén, Ritz, and Greenspan (1983) have reported that, for experienced subjects, the pain-detection threshold averages $12 \mathrm{~mA}(0.6 \mathrm{~mA} /$ $\mathrm{mm}^{2}$ ) for direct current. The current densities used in the present experiments were always less than the reported pain threshold value reported by Vierck et al. (1983), with our highest stimulus value being $0.018 \mathrm{~mA} /$ $\mathrm{mm}^{2}$ (at $22 \mathrm{~mA}$ ). However, it is difficult to compare studies that use different electrodes, because electrode configuration is an important factor in determining pain intensity (Tursky, 1974). In addition, the total applied current in the present experiment was sometimes greater than that reported by Vierk et al. for pain threshold. It is possible, therefore, that the pain produced by potassium iontophoresis could, particularly at higher stimulus intensities, be a combination of potassium ion and direct current stimulation of the pain nerve fibers.

To determine the extent to which the pain produced by potassium iontophoresis is a direct result of the applied potassium ions, a sodium control was run in Experiment 3. The sodium $\left(\mathrm{Na}^{+}\right)$ion was selected as the control. Most pain studies using electrical stimulation do not use dry electrodes so as to prevent skin irritation and burning, and saline (sodium-chloride-based) solutions or gels are commonly used.

In Experiment 3, the psychophysical functions that were investigated in Experiments 1 and 2 were determined with 9 previously untested subjects and with the stimuli presented randomly rather than constrained to four intensity levels.

\section{Method}

Apparatus. The only change from the apparatus described in the general section was that the $3 \% \mathrm{w} / \mathrm{v}$ potassium chloride anode gel was replaced with a $3 \% \mathrm{w} / \mathrm{v}$ sodium chloride anode gel for the sodium condition.

Procedure. In each of two daily sessions, the subjects were exposed to $601-\mathrm{sec}$ stimuli, with an ISI of $15 \mathrm{sec}$. Because of individual variation in pain responsivity, the range of stimulus intensity levels was not the same for all subjects. Stimulus intensities ranged from 7 to $22 \mathrm{~mA}(2.87-9.02 \mu \mathrm{g} \mathrm{K}+/ \mathrm{sec})$. In the first session, the stimulus intensities varied randomly but were always in whole milliamp units. The second session repeated the trial sequence of the first session. The order of presentation of the potassium or sodium ions was counterbalanced across the two sessions.

\section{Results and Discussion}

Coefficients of determination for the linear, logarithmic, and power functions (Table 5) were consistent with the results in Experiments 1 and 2. For the potassium condition, the linear function provided a significantly better description of the stimulus-response relationship than did the power function $[t(8)=3.02, p<.05]$.

The overall potassium power exponent was significantly smaller than the sodium exponent (Table 5) $[t(8)=$ $5.06, p<.01]$. While, in terms of delivered current and sequence of trials for each subject, the pain stimuli were identical for both the sodium and potassium iontophoresis conditions, there was a significantly greater average range of responding for the potassium condition 
(123 mm), relative to that for the sodium condition $(94 \mathrm{~mm})[t(8)=2.90, p<.05]$. This indicates that the effective stimulus range was greater in the potassium condition, due to the ability of potassium to generate higher pain levels. Intramodal range effects (Poulton, 1968; R. Teghtsoonian, 1973), in which larger stimulus ranges tend to produce smaller power exponents, are consistent, then, with the overall lower potassium power exponent obtained. However, if a range effect was producing the exponent difference, then we would expect a significant negative correlation between the percentage change in response range (as an indicator of change in effective stimulus range) and percentage change in power exponent. For our 9 subjects, there was no significant relationship $(r=-.14)$. Clearly, differential nociceptive effects of the sodium and potassium ions override any intramodal range effect that may also be influencing the power exponents.

In sum, in addition to electrode configuration (Higashiyama \& Tashiro, 1990; Tursky, 1974), the nature of the electrolyte that carries the applied current across the dermal barrier can influence the psychophysical parameters that describe the stimulus-response relationship. Thus, it could be difficult to compare studies using different conducting pastes formulated with different active electrolytes, even if those studies have used the same electrical parameters and electrode configurations.

Figure 3 shows the linear regression lines for each subject for the sodium and potassium conditions. For all subjects (except Subject 7), the potassium iontophoresis produced higher levels of pain at all stimulus intensities. For the lowest, median, and highest stimuli levels, there were significant differences in pain response to the sodium and potassium stimuli (see Table 6).

There is a large amount of individual variability in how much potassium iontophoresis increases the painfulness of a given applied current, relative to that produced by sodium iontophoresis. For most subjects, however, the increase was substantial. In addition, the

Table 5

Coefficient of Determination ( $r^{2}$ ) for Linear, Logarithmic, and Power Functions for the Relationship Between Iontophonetic Potassium Stimulus and Pain Report on the Pain-Intensity VAS for the Potassium ( $\left.{ }^{+}\right)$and Sodium $\left(\mathrm{Na}^{+}\right)$Groups in Experiment 3

\begin{tabular}{|c|c|c|c|c|c|c|}
\hline \multirow[b]{3}{*}{ Subject } & \multicolumn{6}{|c|}{ Function } \\
\hline & \multicolumn{2}{|c|}{ Linear } & \multicolumn{2}{|c|}{ Logarithmic } & \multicolumn{2}{|c|}{ Power } \\
\hline & $\mathrm{Na}^{+}$ & $\mathrm{K}^{+}$ & $\mathrm{Na}^{+}$ & $\mathrm{K}^{+}$ & $\mathrm{Na}^{+}$ & $\mathrm{K}^{+}$ \\
\hline 1 & .85 & .96 & .83 & .96 & $.84(3.52)$ & $.94(2.28)$ \\
\hline 2 & .83 & .89 & .76 & .87 & $.86(3.33)$ & $.87(3.15)$ \\
\hline 3 & .89 & .92 & .84 & .93 & $.88(2.99)$ & $.88(1.32)$ \\
\hline 4 & .79 & .89 & .74 & .87 & $.82(2.47)$ & $.85(1.43)$ \\
\hline 5 & .95 & .92 & .94 & .94 & $.93(3.35)$ & $.80(2.72)$ \\
\hline 6 & .86 & .88 & .83 & .89 & $.90(2.98)$ & $.84(2.03)$ \\
\hline 7 & .91 & .89 & .91 & .87 & $.84(3.33)$ & $.87(2.63)$ \\
\hline 8 & .86 & .85 & .80 & .79 & $.79(2.09)$ & $.72(1.91)$ \\
\hline 9 & .81 & .84 & .77 & .87 & $.80(3.15)$ & $.83(1.60)$ \\
\hline Average & .86 & .89 & .82 & .89 & $.85(3.02)$ & $.84(2.12)$ \\
\hline
\end{tabular}

Note-Exponents for power functions given in parentheses.
Table 6

\begin{tabular}{|c|c|c|c|}
\hline Stimulus Level & $\begin{array}{c}\mathrm{Na}^{+} \\
\operatorname{VAS}(\mathrm{mm})\end{array}$ & $\begin{array}{c}\mathbf{K}^{+} \\
\operatorname{VAS}(\mathrm{mm}) \\
\end{array}$ & $\begin{array}{c}\text { Significance of } \\
\text { Difference }\end{array}$ \\
\hline Lowest & 5 & 17 & $t(8)=4.39^{*}$ \\
\hline Median & 32 & 74 & $t(8)=5.78^{*}$ \\
\hline Highest & 78 & 120 & $t(8)=3.84^{*}$ \\
\hline
\end{tabular}

${ }^{*} p<.01$.

subjects were more likely to spontaneously report the potassium stimulus as producing a burning effect.

\section{GENERAL DISCUSSION}

Potassium iontophoresis possesses many of the characteristics required of an experimental pain stimulus. By interview at the conclusion of the experiments, a qualitative description of the stimulus was obtained. The stimulus was rated genuinely painful by all subjects. At low stimulus intensities, it was typically described as a pricking/stinging sensation; at higher intensities, it was reported as a deep, widespread burning sensation. Many subjects commented on the "nonelectrical" nature of the stimulus, in that it did not produce an expected electric shock sensation.

The sodium control demonstrated that the perceived pain was substantially the result of the specific painproducing action of the potassium ion. This is consistent with previous studies that have demonstrated the nociceptive action of potassium. However, there were large unexplained individual differences in the increase in perceived pain as a result of the potassium administration, relative to the sodium control. The extent that this indicates systematic differences in reaction to the potassium administration, or is partly a methodological artifact arising from testing subjects across days, is uncertain.

The stimulus is easy to quantify. The relationship between potassium infusion and applied direct current makes it possible to precisely determine and deliver selected quantities of potassium ion. The results of the present study showed that a two-constant linear function provided the best description of the relationship between applied stimulus and pain report over a range that is most often encountered with clinical pain. It is also possible that a three-constant power function (i.e., a power function with a threshold correction; e.g., Higashiyama $\&$ Tashiro, 1987) would provide an even better fit. However, such an improved fit may not reflect an actual underlying power psychophysical function; it may simply be the result of a three-constant function's ability to better fit monotonically increasing data.

McCallum and Goldberg (1975) have argued that criteria aside from goodness of fit should be used in deciding whether a linear function should be discarded for more complex functions. In pain research, neural processing should supply the most appropriate criterion. Unfortunately, pain perception is the result of complex 

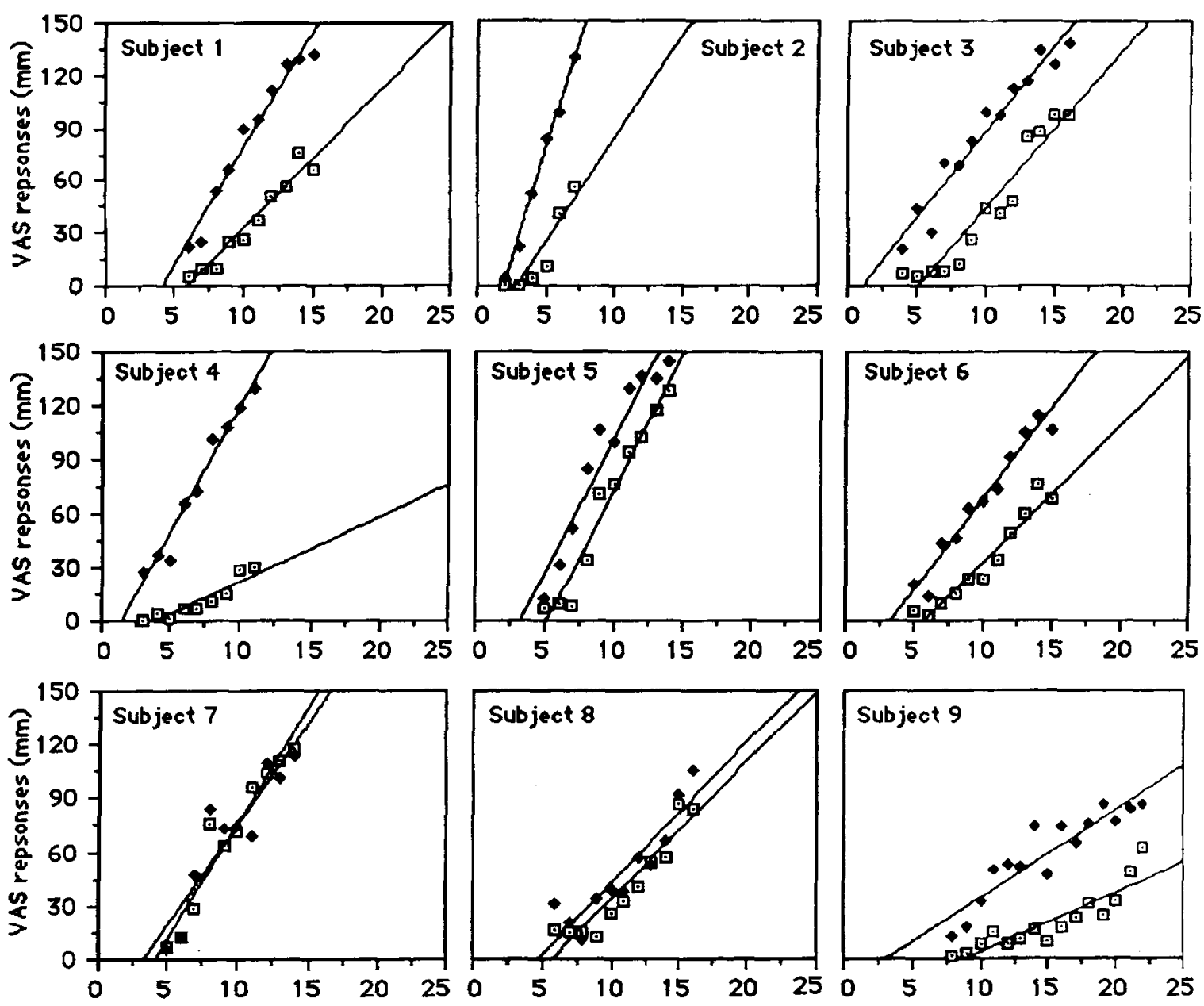

Figure 3. The linear regression lines for each subject for sodium and potassium iontophoresis in Experiment 3. The data points are the arithmetic means for responses at each stimulus level. The squares represent the sodium iontophoresis; the closed triangles represent the potassium iontophoresis.

neural processing at both the peripheral and the central level. It is unlikely that our knowledge of such processes will let us a priori decide which function should best be applied to psychological pain reports for some time. Furthermore, if the functions reflect context effects (Algom \& Marks, 1990; Foley, Cross, \& O'Reilly, 1990; Gescheider \& Hughson, 1991) in addition to the nociceptive processing, interpretation is made even more difficult. Finally, unless it can be demonstrated to confer some evolutionary advantage, there is no reason to expect the evolutionary forces that have shaped pain perception to have constrained the underlying physiological processes to fit any simple psychophysical law.

It is possible to produce any pain intensity from threshold to tolerance levels (though, in the present experiments, threshold and tolerance pain levels of stimulation were not used). Even with higher stimulus intensity levels and repeated trials, there is no apparent tissue damage. A mild reddening of the skin that disappeared within minutes was the most noticeable reaction that occurred, and then only in some subjects. The reddening some- times took the form of isolated patches approximately $2-3 \mathrm{~mm}$ in diameter both inside and outside of the anode site. The occurrence of a response away from the electrode site suggested that the inflammation was neurally modulated, rather than a direct effect of the applied potassium ions.

Potassium iontophoresis provides an opportunity to investigate the neural modulation of pain in the relative absence of inflammation processes and tissue damage, even with high stimulus intensities. In contrast, at high stimulus intensities with repeated stimulation, many experimental pain stimuli (e.g., thermal or mechanical) can produce substantial tissue trauma, with the attendant direct release of pain-producing chemicals, such as histamine, serotonin, various kinins, and prostaglandins (Hurley, 1984). While this may confer some clinical validity for these stimuli, the ability to study reactions to painful stimulation relatively isolated from these tissue trauma processes could provide a useful analytical tool.

The combined results of Experiments 1 and 2 indicate that short-duration iontophoretic stimuli of $1 \mathrm{sec}$ can be 
applied rapidly with no substantial loss in subject response consistency over repeated trials, in terms of both immediate trial-to-trial effects and session effects. This was found to be particularly so for moderate-intensity pain stimuli. Clearly, these are desirable characteristics for an experimental pain stimulus.

The finding of adaptation for low-intensity pain stimuli and enhanced responding for moderate-intensity pain stimuli across a session (Experiment 2) may be a result of the differences in responding between $\mathrm{A}$-delta and $\mathrm{C}$ fibers. $C$-fiber activity has been associated with burning pain, whereas A-delta activity has been associated with pricking pain (Torebjörk \& Hallin, 1973; Torebjörk \& Ochoa, 1980; Willis, 1985, p. 37). For example, Price (1972) found that first pain, mediated by A fibers, produced a pricking sensation, whereas second pain, mediated by $\mathrm{C}$ fibers, had a burning or throbbing quality. In the present study, the subject's reports of a pricking pain at low stimulus intensities and burning sensations at higher stimulus levels suggests that A-delta adaptation and C-fiber sensitization may have occurred across a session. Lahoda et al. (1977) have reported habituation across a session for electric shock that produced a "pricking pain sensation" (p. 52). Primate studies have found that adaptation can occur in A-delta nociceptors with repeated stimulation (e.g., Georgopoulos, 1976; Perl, 1968).

The results of Experiment 2 highlight that both ISI and stimulus intensity are crucial factors when investigating stimulus history effects. This applies to both overall session effects and the changes produced by immediately preceding stimuli. Most previous studies have not attempted to measure the interaction between painstimulus intensity and ISI. The results of the present study show that a detailed understanding of pain processing can only be developed by taking such interactions into account. For example, whether there was suppression or enhancement of pain response was dependent on the ISI, the preceding stimulus intensity, and the present stimulus intensity.

Further studies need to clarify the extent to which the short-term effects of prior stimuli are due to general sequential dependency and other response bias factors or are intrinsic to the neural modulation of pain. The magnitude of the carry-over effects observed suggests that nociceptive processing is the main factor.

\section{REFERENCES}

Algom, D., \& Marks, L. E. (1990). Range and regression, loudness scales, and loudness processing: Toward a context-bound psychophysics. Journal of Experimental Psychology: Human Perception \& Performance, 16, 706-727.

Algom, D., RaphaEli, N., \& Cohen-Raz, L. (1986). Integration of noxious stimulation across separate somatosensory communication systems: A functional theory of pain. Journal of Experimental Psychology: Human Perception \& Performance, 12, 92-102.

armstrong, D., Dry, R. M. L., Keele, C. A., \& Markham, J. W. (1953). Observations on chemical excitants of cutaneous pain in man. Journal of Physiology, 120, 326-351.

BeCK, C., \& RosNer, B. S. (1968). Magnitude scales and somatic evoked potentials to percutaneous electrical stimulation. Psychophysiology \& Behaviour, 3, 949-983.
BENJAMIN, F. B. (1959). Release of intracellular potassium as the physiological stimulus for pain. Journal of Applied Physiology, 14, 643-646.

Benjamin, F. B., \& HelveY, W. M. (1963). Iontophoresis of potassium for experimental determination of pain endurance in man. Proceedings of the Society for Experimental Biology \& Medicine, 113, 566-568.

Chudler, E. H., Anton, F., Dubner, R., \& Kenshalo, D. R. (1990). Responses of nociceptive SI neurons in monkeys and pain sensation in humans elicited by noxious thermal stimulation: Effect of interstimulus interval. Journal of Neurophysiology, 63, 559-569.

ClaRK, W. C., \& Goodman, J. S. (1974). Effects of suggestion on $d^{\prime}$ and $\mathrm{Cx}$ for pain detection and pain tolerance. Journal of Abnormal Psychology, 83, 364-372.

CoYne, T. M., \& PeCK, C. (1980). Pain and depression as a function of effectiveness of perceived control. In $\mathrm{C}$. Peck \& $\mathrm{M}$. Wallace (Eds.), Problems in pain (pp. 121-127). Sydney: Pergamon.

Cross, D. V., TURSKY, B., \& LODGE, M. (1975). The role of regression and range effects in the determination of the power function for electric shock. Perception \& Psychophysics, 18, 9-14.

FIORGIONE, A. G., \& BARBER, T. X. (1971). A strain gauge pain stimulator. Psychophysiology, 8, 102-106.

Foley, H. J., Cross, D. V., \& O'Rerlly, J. A. (1990). Pervasiveness and magnitude of context effects: Evidence for the relativity of absolute magnitude estimation. Perception \& Psychophysics, 48, 551-558.

GeERTSMA, R. H. (1958). Time-order errors in comparative judgments of hurtfulness. Journal of Experimental Psychology, 55, 284-288.

GELDARD, F. A. (1972). The human senses (2nd ed.). New York: Wiley. GEORGopoulos, A. P. (1976). Functional properties of primary afferent units probably related to pain mechanisms in primate glabrous skin. Journal of Neurophysiology, 39, 71-83.

Gescheider, G. A. (1988). Psychophysical scaling. Annual Review of Psychology, 39, 169-200.

Gescheider, G. A., \& Hughson, B. A. (1991). Stimulus context and absolute magnitude estimation: A study of individual differences. Perception \& Psychophysics, 50, 45-57.

Guilbaud, G. (1988). Peripheral and central electrophysiological mechanisms of joint and muscle pain. In R. Dubner, G. F. Gebhart, \& M. R. Bond (Eds.), Proceedings of the Vth World Congress on Pain (pp. 201-215). Amsterdam: Elsevier.

Handwerker, H. O., \& Kobal, G. (1993). Psychophysiology of experimentally induced pain. Physiological Reviews, 73, 639-671.

HARDY, J. D., WolFF, H. G., \& GoOdELL, H. (1950). Experimental evidence on the nature of cutaneous hyperalgesia. Journal of Clinical Investigation, 29, 115-140.

HARDY, J. D., WolfF, H. G., \& Goodell, H. (1967). Pain sensations and reactions. New York: Hafner.

Higashiyama, A., \& Tashiro, T. (1987). Magnitude estimates for electric shock. Japanese Psychological Research, 29, 81-88.

Higashiyama, A., \& Tashiro, T. (1989). Magnitude estimates for electrical pulses: Evidence for two neural mechanisms. Perception \& Psychophysics, 45, 537-549.

HigashiYama, A., \& TASHiRo, T. (1990). Electrocutaneous spatial integration at threshold: The effects of electrode size. Perception \& Psychophysics, 48, 389-397.

Humphries, S. A., \& JoHnson, M. H. (1990, April). The reliability and validity of iontophoretically applied potassium ions as an experimental pain stimulus. Paper presented at the Vth World Congress on Pain, Adelaide.

HuRLeY, J. V. (1984). Inflammation. In J. R. Anderson (Ed.), Muir's textbook of pathology (12th ed., pp. 4.1-4.38). London: Edward Arnold.

JONES, B. (1980). Algebraic models for integration of painful and nonpainful electric shocks. Perception \& Psychophysics, 28, 572-576.

JONES, B., \& GWYNN, M. (1984). Functional measurement scales of painful electric shocks. Perception \& Psychophysics, 35, 193-200.

Jones, B., Planas, M., \& Anuza, T. (1982). Painfulness decreases the discriminability of electric shock. Perception \& Psychophysics, 32, 187-191.

Keele, K. D. (1975). A physician looks at pain. In M. Weisenberg (Ed.), Pain: Clinical and experimental perspectives (pp. 45-52). St. Louis: Mosby.

Kenshalo, D. R., JR., Anton, F., \& Dubner, R. (1989). The detection and perceived intensity of noxious thermal stimuli. Journal of Neurophysiology, 62, 429-436. 
Kumazawa, T., \& Mizumura, K. (1977). Thin-fibre receptors responding to mechanical, chemical, and thermal stimulation in the skeletal muscle of the dog. Journal of Physiology, 273, 179-194.

Lahoda, R, Stacher, G., \& Bauer, P. (1977). Experimentally induced pain: Measurement of pain threshold and pain tolerance using a new apparatus for electrical stimulation of the skin. International Journal of Clinical Pharmacology, 15, 5l-56.

LAMING, D. (1989). Experimental evidence for Fechner's and Steven's laws. Behavioural \& Brain Sciences, 12, 277-278.

LAMotTe, R. H., \& CAMPBELL, J. N. (1978). Comparison of responses of warm and nociceptive C-fibre afferents in monkey with human judgments of thermal pain. Journal of Neurophysiology, 41, 509-529.

LaMotte, R. H., Shain, C. N., Simone, D. A., \& Tsai, E.-F. P. (1991). Neurogenic hyperalgesia: Psychophysical studies of underlying mechanisms. Journal of Neurophysiology, 66, 190-211.

Lamotte, R. H., Thalhammer, J. G., \& Robinson, C. J. (1983). Peripheral neural correlates of magnitude of cutaneous pain and hyperalgesia: A comparison of neural events in monkey with sensory judgments in human. Journal of Neurophysiology, 50, 1-26.

LlOYD, M. A., \& APPEL, J. B. (1976). Signal detection theory and the psychophysics of pain: An introduction and review. Psychosomatic Medicine, 38, 79-94.

McCormack, H. M., Horne, D. J. D. L., \& Sheather, S. (1988). Clinical applications of visual analogue scales: A critical review. Psychological Medicine, 18, 1007-1019.

McCallum, P., \& Goldberg, H. (1975). Magnitude scales for electrocutaneous stimulation. Perception \& Psychophysics, 17, 75-78.

Ong, B., Singer, G., \& Wallace, M. (1980). Pain sensations produced by alogens in humans. In C. Peck \& M. Wallace (Eds.), Problems in pain (pp. 101-110). Sydney: Pergamon.

Parker, S., Casey, J., Ziriax, J. M., \& Silberberg, A. (1988). Random monotone data fit simple algebraic models: Correlation is not confirmation. Psychological Bulletin, 104, 417-423.

PERL, E. R. (1968). Myelinated afferent fibers innervating the primate skin and their response to noxious stimuli. Journal of Physiology, 197, 593-615.

Poulton, E. C. (1968). The new psychophysics: Six models for magnitude estimation. Psychological Bulletin, 69, 1-19.

Poulton, E. C. (1975). Range effects in experiments on people. American Journal of Psychology, 88, 3-32.

Poulton, E. C. (1979). Models for biases in judging sensory magnitude. Psychological Bulletin, 86, 777-803.

Poulton, E. C. (1984). A linear relation between loudness and decibels. Perception \& Psychophysics, 36, 338-342.

PRICE, D. D. (1972). Characteristics of second pain and flexion reflexes indicative of prolonged central summation. Experimental Neurology, 37, 371-387.

Price, D. D. (1988). Psychological and neural mechanisms of pain. New York: Raven Press.

Price, K. P., \& TURSKY, B. (1975). The effect of varying stimulus parameters on judgments of nociceptive electrical stimulation. Psychophysiology, 12, 663-666.

Procacci, P., \& Maresca, M. (1984). General considerations in pain measurement in man. In B. Bromm (Ed.), Pain measurement in man: Neurophysiological correlates of pain (pp. 431-434). New York: Elsevier.

Rollman, G. B., \& Harris, G. (1987). The detectability, discriminability, and perceived magnitude of painful electric shock. Perception \& Psychophysics, 42, 257-268.
Stam, H. J., Petrusic, W. M., \& Spanos, N. P. (1981). Magnitude scales for cold pressor pain. Perception \& Psychophysics, 29, 612-617.

Stevens, S. S. (1965). Matching functions between loudness and ten other continua. Perception \& Psychophysics, 1, 5-8.

Stevens, S. S., Carton, A. S., \& Shickman, G. M. (1958). A scale of apparent intensity of electric shock. Journal of Experimental Psychology, 56, 328-334.

Teghtsoonian, M., \& Teghtsoonian, R. (1983). Consistency of individual exponents in cross-modal matching. Perception \& Psychophysics, 33, 203-214.

TEGHTSOONIAN, R. (1973). Range effects in psychophysical scaling and a revision of Stevens' law. American Journal of Psychology, 86, 3-27.

Teghtsoonian, R., \& Teghtsoonian, M. (1986). Scaling loudness over short ranges: A reply to Poulton. Perception \& Psychophysics, 39, 73-75.

Torebjörk, H. E., \& Hallin, R. G. (1973). Perceptual changes accompanying controlled preferential blocking of $\mathrm{A}$ and $\mathrm{C}$ fibre responses in intact human nerves. Experimental Brain Research, 16, 321-332.

Torebjörk, H. E., LaMotte, R. H., \& Robinson, C. J. (1984). Peripheral neural correlates of magnitude of cutaneous pain and hyperalgesia: Simultaneous recordings in humans of sensory judgments of pain and evoked responses in nociceptors with C-fibers. Journal of Neurophysiology, 51, 325-339.

TOREBJÖRK, H. E., \& OCHOA, J. L. (1980). Specific sensations evoked by activity in single identified sensory units in man. Acta Physiologica Scandinavica, 110, 445-447.

Tursky, B. (1974). Physical, physiological, and psychosocial factors that affect pain reaction to shock. Psychophysiology, 11, 95-112.

Uchida, Y., \& Murao, S. (1974). Potassium-induced excitation of afferent cardiac sympathetic nerve fibers. American Journal of Physiology, 226, 603-607.

Vierck, C. J., CoOper, B. Y., Franzén, O., Ritz, L. A., \& Greenspan, J. D. (1983). Behavioural analysis of CNS pathways and transmitter systems involved in conduction and inhibition of pain sensations and reactions in primates. In J. M. Sprague \& A. N. Epstein (Eds.), Progress in psychobiology \& physiological psychology (Vol. 10, pp. 113-165). New York: Academic Press.

Voudouris, N. J., Peck, C., \& Coleman, G. (1985). Conditioned placebo responses. Journal of Personality \& Social Psychology, 48, 47-53.

Voudouris, N. J., PeCK, C., \& Coleman, G. (1989). Conditioned response models of placebo phenomena: Further support. Pain, 38, 109-116.

WALL, P. D. (1988). Stability and instability of central pain mechanisms. In R. Dubner, G. F. Gebhart, \& M. R. Bond (Eds.), Proceedings of the Vth World Congress on Pain (pp. 13-24). Amsterdam: Elsevier.

WiLLIS, W. D. (1985). The pain system. New York: Karger.

WolfF, B. B. (1977). The role of laboratory pain induction methods in the systematic study of human pain. Acupuncture \& ElectroTherapeutics Research, 2, 271-305.

ZWETNOW, N. N. (1979). The significance of experimental work in pain research. In J. W. Beks (Ed.), The management of pain (pp. 196211). New York: Elsevier.

(Manuscript received March 10, 1993; revision accepted for publication June 19, 1994.) 